\title{
Indicadores físicos de um latossolo amarelo distrófico sob adubação verde
}

A adubação verde é uma prática que pode trazer melhorarias nas condições físicas, químicas e biológicas do solo e contribuir para mitigação do uso do fogo na agricultura migratória. Ess estudo avalia os efeitos da adubação verde utilizando três leguminosas e dois anos de cultivo em um Latossolo Amarelo distrófico através de indicadores físicos da qualidade do solo. 0 delineamento experimental foi em blocos casualizados em esquema de parcelas subdivididas. As parcelas foram compostas por quatro coberturas: Mucuna aterrima, Canavalia ensiformis, Vigna unguiculata e vegetação espontânea (testemunha), as subparcelas por dois anos de cultivo (2017 e 2018), com 6 repetições. Avaliou-se a produtividade de fitomassa e os indicadores de qualidade física: densidade do solo e a resistência à penetração. As espécies Mucuna aterrima e Canavalia ensiformis apresentaram as maiores produtividades de massa fresca e seca. Não houve diferenças entre as coberturas para densidade do solo. Contudo, para a resistência a penetração, o feijão caupi mostrou-se pouco eficiente comparado a Mucuna aterrima e vegetação houve diferenças entre as coberturas para densidade do solo. Contudo, para a resistência a penetração, o feijão caupi mostrou-se pouco eficiente comparado a Mucuna aterrima e vegetação comparado a análise prévia da área de cultivo aos dois anos de cultivo, observa-se reduções apenas na resistência à penetração da camada de $0-20 \mathrm{~cm}$ onde houve as maiores deposições de resíduos vegetais. Portanto, dentre as leguminosas avaliadas, a mucuna-preta e o feijão-de-porco possuem melhores potenciais produtivo de fitomassa. Nas condições edafoclimáticas do estudo, as coberturas não proporcionam alteraçães nos atributos físicos do solo, com exceção do feijão caupi que apresentou efeitos negativos, não sendo recomendado como cobertura, quando se objetiva a melhoria das propriedades físicas do solo. Os anos de cultivo contribuíram para uma melhora nos atributos físicos do solo, reduzindo a densidade e a resistência à penetração.

Palavras-chave: Leguminosas; Densidade do solo; Resistência à penetração; Umidade.

\section{Physical indicators of a dystrophic yellow latosol under green manure}

\begin{abstract}
Green manure is a practice that can improve the physical, chemical and biological conditions of the soil and contribute to mitigating the use of fire in migratory agriculture. This study evaluates Green manure is a practice that can improve the physical, chem blocks in a split-plot scheme. The plots were composed of four coverings: Mucuna aterrima, Canavalia ensiformis, Vigna unguiculata and spontaneous vegetation (control), the subplots for blocks in a split-plot scheme. The plots were composed of four coverings: Mucuna aterrima, Canavalia ensiformis, Vigna unguiculata and spontaneous vegetation (control), the subplots for
two years of cultivation (2017 and 2018), with 6 replicates. Phytomass productivity and physical quality indicators were evaluated: soil density and resistance to penetration. The species M. aterrima and $\mathrm{C}$. ensiformis presented the highest yields of fresh and dry mass. There were no differences between the coverages for soil density. However, for penetration resistance, $\mathrm{V}$. unguiculata proved to be inefficient compared to $\mathrm{M}$. aterrima and spontaneous vegetation. After two years of cultivation, there was a decrease in density in the surface layer (0-10 $\mathrm{cm}$ ) and in resistance to penetration of the subsurface layer $(20-40 \mathrm{~cm})$. However, when comparing the previous analysis of the cultivation area to two years of cultivation, there are reductions only in the resistance to penetration of the $0-20 \mathrm{~cm}$ layer where there was the greatest deposition of plant residues. Therefore, among the evaluated legumes, $\mathrm{M}$. aterrima and $\mathrm{C}$. ensiformis have better phytomass production potentials. Under the edaphoclimatic conditions of the study, the coverings do not alter the physical attributes of the soil, except for $V$. unguiculata, which presented negative effects and is not recommended as cover, when the objective is to improve the physical properties of the soil. The years of cultivation contributed to an improvement in the physical attributes of the soil, reducing density and resistance to penetration.
\end{abstract}

Keywords: Legumes; Soil density; Resistance to penetration; Moisture.

Topic: Agroecologia

Reviewed anonymously in the process of blind peer.
Received: 04/10/2020

Approved: $\mathbf{2 1 / 1 1 / 2 0 2 0}$
Romário Martins Costa (iD)

Universidade Federal do Piauí, Brasil http://lattes.cnpq.br/8193853986166353

http://orcid.org/0000-0001-5429-4663 romario.martins90@hotmail.com

Sâmia dos Santos Matos (D)

Universidade Federal do Piauí, Brasil http://lattes.cnpq.br/0156452279835438

http://orcid.org/0000-0002-4573-9277

samiamatos2011@hotmail.com

Rayssa Carolinne Mouzinho de Sousa (D) Universidade Federal do Piauí, Brasil http://lattes.cnpq.br/6135660736968929 http://orcid.org/0000-0002-1478-872X rayssamouzinho@gmail.com
Marcos Renan Lima Leite (iD) Universidade Federal do Piauí, Brasil http://lattes.cnpq.br/7363525329923328 http://orcid.org/0000-0002-2910-9232 marcos lleite@hotmail.com

Maryzélia Furtado de Farias (iD Universidade Federal do Maranhão, Brasil http://lattes.cnpq.br/2230366525752958 http://orcid.org/0000-0001-9078-1354 maryzelia@ig.com.br

\section{Mariléia Barros Furtado (D)}

Universidade Federal do Maranhão, Brasil http://lattes.cnpq.br/0177700018215014 http://orcid.org/0000-0003-4696-2136 marileiafurtado@hotmail.com
Luisa Julieth Parra Serrano (it) Universidade Federal do Maranhão, Brasi http://lattes.cnpq.br/6001864868903542 http://orcid.org/0000-0002-9796-1988 julieth ps@yahoo.com

\section{Referencing this:}

COSTA, R. M.; MATOS, S. S.; SOUSA, R. C. M.; LEITE, M. R. L.; FARIAS, M. F.; FURTADO, M. B.; SERRANO, L. J. P.. Indicadores físicos de um latossolo amarelo distrófico sob adubação verde. Revista lbero Americana de Ciências Ambientais, v.11, n.6, p.141-149, 2020. DOI: http://doi.org/10.6008/CBPC2179-6858.2020.006.0013 


\section{INTRODUÇÃO}

Devido à crescente preocupação com a manutenção da qualidade dos solos e a sustentabilidade dos sistemas agrícolas, estudos vêm sendo realizados com o intuito de verificar a qualidade do solo, seja sob a utilização de diferentes sistemas de manejo, seja sob a aplicação de diferentes fontes de adubação, adotando para isso indicadores da qualidade física, química e biológica dos solos (CHERUBIN et al., 2015, MELO et al., 2017). De acordo com Oliveira et al. (2015), existem vários indicadores que são eficientes para determinação da qualidade física dos solos, dentre estes estão os atributos físicos: densidade do solo, resistência do solo à penetração, porosidade total, macroporosidade, razão macro e microporosidade. Estes indicadores podem ser usados para diagnósticos mais precisos do estado físico desses solos.

O atributos físicos-hídricos, tal como a resistência à penetração e velocidade de infiltração da água no solo são diretamente influenciados pelos diferentes sistemas de uso e manejos dos solos (FARIAS et al. 2017). Os solos do estado do Maranhão em sua grande maioria são classificados como Latossolos, esses requerem um sistema com incremento de matéria orgânica visto que são formados por minerais menos resistentes e possuem alta intemperização, são profundos, geralmente com acidez elevada e baixa fertilidade natural (SANTOS et al., 2013). Na Mesorregião Leste maranhense, além das características supracitadas, existem solos que apresentam camadas com caráter coeso, tornando-se um limitante para a produção agrícola (DANTAS et al., 2014).

Quanto ao nível tecnológico empregado nesse estado, houve uma melhora nos últimos anos em decorrência da diversificação das culturas plantadas, no entanto, práticas da agricultura itinerante ainda são amplamente empregadas na maioria dos estabelecimentos agropecuários (CASTRO, 2012). A agricultura itinerante é caracterizada pela derrubada e queima da vegetação, promovendo um aumento temporário da fertilidade e do pH do solo, assim, após pouco tempo de cultivo, geralmente de 2 a 3 anos, há uma drástica redução na produtividade das culturas, o que obriga os agricultores a migrarem para outras áreas, deixando a área improdutiva em pousio por vários anos (COSTA et al., 2015; JESUS et al., 2015).

Para que os agricultores dessa região abandonem a agricultura itinerante e possam praticar uma agricultura sustentável é necessário à adoção de práticas que possa melhorar tanto a fertilidade do solo através da libertação lenta de nutrientes, como também sua estrutura física e atividade microbiológica (MOURA et al., 2016). Como alternativa, pode ser empregada à adubação verde, que é uma prática de cultivo de espécies vegetais em rotação ou consórcio, que após o corte são deixadas sobre o solo ou incorporadas (CARDOSO et al., 2014).

Várias espécies de plantas podem ser utilizadas como adubos verdes, destacando-se as leguminosas por apresentarem associação simbiótica com bactérias fixadoras de nitrogênio, tornando-se uma boa alternativa para reposição do nitrogênio extraído do solo pelas culturas (PEREIRA et al., 2017). Outro efeito benéfico gerado por essa prática para as características químicas do solo, está relacionado à reciclagem de nutrientes, pois, parte dos nutrientes absorvidos pelas raízes das leguminosas em camadas subsuperficiais são liberados sobre o solo com a decomposição dos resíduos após o corte (CARDOSO et al., 2014). 
Segundo Souza et al. (2011), o fornecimento de matéria orgânica (MO) pelos adubos verdes além de aumentar os estoques de MO e carbono do solo, também influencia na sua qualidade física, como no aumento da agregação e da estruturação, porosidade, capacidade de retenção e armazenamento de água, promovendo uma redução da densidade do solo e consequentemente, da resistência mecânica à penetração das raízes.

A produtividade de biomassa das plantas utilizadas como adubos verdes é influenciada diretamente pelas espécies utilizadas e por fatores edafoclimáticos. Nesse sentido, fazem-se necessários estudos para verificar o potencial produtivo de espécies adaptadas, com capacidade para atuarem na proteção e regeneração das propriedades físicas do solo, avaliados através de indicadores de qualidade do solo com o intuito de gerar informações que possam servir de base para agricultores da região. Assim, objetivou-se com este estudo avaliar os efeitos da adubação verde utilizando três leguminosas e dois anos de cultivo em um Latossolo Amarelo distrófico através de indicadores físicos da qualidade do solo.

\section{MATERIAIS E MÉTODOS}

O experimento foi instalado e conduzido em condições de campo no Centro de Ciências Agrárias e Ambientais da Universidade Federal do Maranhão, Chapadinha/MA, sob as coordenadas: 344'08.08"S e 431'56.41"O, no período de janeiro de 2017 a junho de 2018. O clima da região é caracterizado como equatorial semiúmido com precipitação média anual de $2100 \mathrm{~mm}$ ano-1 e duas estações bem definidas, uma estação chuvosa que se estende de janeiro a junho e uma estação seca de julho a dezembro (MOURA-SILVA et al., 2016), com temperatura anual média superior a 27 ㄷ (INMET, 2018). Os dados de precipitação pluviométrica e temperatura mensal durante a condução do estudo estão apresentados na Figura 1.

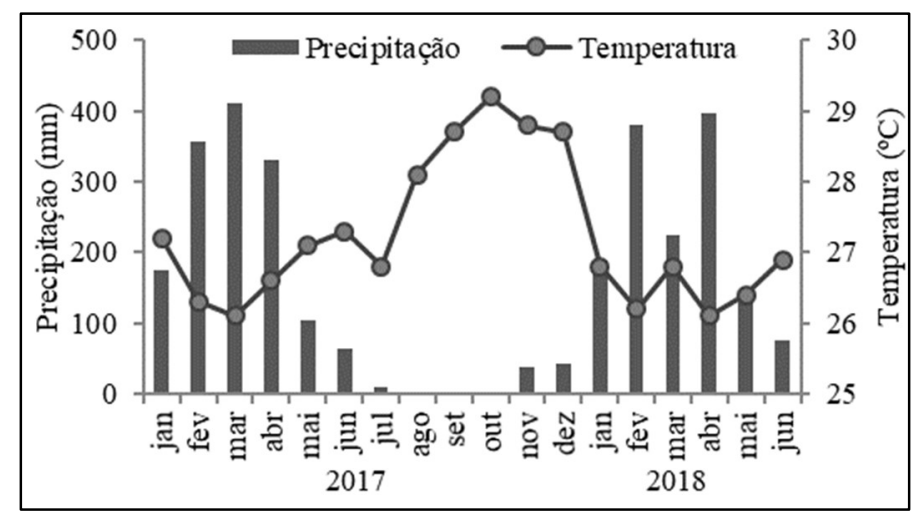

Figura 1: Médias de precipitação e temperatura nos dois anos (2017 e 2018) de avaliação do estudo na área experimental no município de Chapadinha, MA, Brasil. Fonte: INMET (2018).

O solo é classificado como Latossolo Amarelo distrófico - LAd (SANTOS et al., 2013), de textura franco arenosa, cuja granulometria é apresentada na Tabela 1. Para caracterização química da área experimental foram coletadas 10 amostras simples na profundidade $0-20 \mathrm{~cm}$ para compor uma amostra composta representativa. $A$ análise apresentou os seguintes resultados: $\mathrm{MO}=15,1 \mathrm{~g} \mathrm{~kg}^{-1} ; \mathrm{pH}\left(\mathrm{CaCl}_{2}\right)=4,2 ; \mathrm{P}=3,3 \mathrm{mg}$ $\mathrm{dm}^{-3} ; \mathrm{K}^{+}=0,11 \mathrm{cmol} \mathrm{dm}^{-3} ; \mathrm{Ca}^{2+}=0,93 \mathrm{cmol} \mathrm{dm}^{-3} ; \mathrm{Mg}^{2+}=0,43 \mathrm{cmol} \mathrm{dm}^{-3} ; \mathrm{Al}^{3+}=0,32 \mathrm{cmol} \mathrm{dm}^{-3} ; \mathrm{H}^{+}+\mathrm{Al}^{3+}=3,05$ $\mathrm{cmol} \mathrm{dm}^{-3} ; \mathrm{CTC}=4,52 ; \mathrm{cmol} \mathrm{dm}^{-3} ;$ saturação por bases $=32,5 \%$; e saturação por alumínio $=17,86 \%$. Antes da 
implantação do experimento também foi realizada a caracterização física do solo na área total em 24 pontos distintos, cujas determinações de densidade, umidade e resistência à penetração são apresentadas na Tabela 2.

Tabela 1: Composição granulométrica do solo da área experimental nas profundidades de 0-20 e 20-40 cm

\begin{tabular}{lllll}
\hline \multirow{2}{*}{ Prof. $(\mathrm{cm})$} & \multicolumn{4}{l}{ Composição granulométrica $\left(\mathrm{g} \mathrm{kg}^{-1}\right)$} \\
\cline { 2 - 5 } & $\begin{array}{l}\text { Areia Grossa } \\
(2-0,2 \mathrm{~mm})\end{array}$ & Areia fina $(0,02-0,05)$ & $\begin{array}{l}\text { Silte } \\
(0,05-0,002)\end{array}$ & Argila $(<0,002)$ \\
\hline $0-20$ & 290 & 530 & 40 & 140 \\
$20-40$ & 260 & 480 & 100 & 160 \\
\hline
\end{tabular}

Tabela 2: Caracterização da densidade, umidade e resistência do solo à penetração antes da implantação das coberturas do solo na área experimental

\begin{tabular}{|c|c|c|c|c|c|}
\hline \multicolumn{2}{|c|}{ Densidade $\left(\mathrm{Mg} \mathrm{m}^{-3}\right)$} & \multicolumn{2}{|c|}{ Umidade (\%) } & \multicolumn{2}{|c|}{ Resistencia à penetração (MPa) } \\
\hline $\begin{array}{l}0-10 \\
\mathrm{~cm}\end{array}$ & $10-20 \mathrm{~cm}$ & $0-20 \mathrm{~cm}$ & $20-40 \mathrm{~cm}$ & $0-20 \mathrm{~cm}$ & $20-40 \mathrm{~cm}$ \\
\hline 1,48 & 1,59 & 8,94 & 9,48 & 2,73 & 4,93 \\
\hline
\end{tabular}

O estudo foi realizado em uma área que se encontrava em pousio, coberta por plantas espontâneas herbáceas de pequeno porte. Para o presente estudo a área experimental não recebeu nenhum preparo de solo, como: aração, gradagem calagem e adubação mineral. O delineamento experimental foi em blocos casualizados em esquema de parcelas subdivididas, onde as parcelas foram compostas por quatro tipos de coberturas e as subparcelas por 2 anos de cultivo, com seis repetições, sendo as coberturas (adubos verdes): a) mucuna-preta [Mucuna aterrima (Piper \& Tracy) Merr]; b) feijão-de-porco [Canavalia ensiformis L. DC], c) feijão caupi [Vigna unguiculata L. Walp.] cultivar BRS Guariba; d) vegetação espontânea (Testemunha), em parcelas com área de $12 \mathrm{~m}^{2}$.

A semeadura foi realizada no início do período chuvoso (janeiro) para os dois anos. As fileiras foram espaçadas de 0,5 m, com densidade de 4 plantas por metro linear para a mucuna-preta e o feijão-de-porco, e 8 plantas por metro linear para o feijão caupi. Não foi realizada inoculação nas sementes, nem aplicação de fertilizantes.

Nos dois anos de cultivo, as plantas de cobertura foram cortadas em pleno estádio reprodutivo e deixadas sobre a superfície do solo nas suas respectivas parcelas, aos 60, 90 e 120 dias após a semeadura, para o feijão caupi, feijão-de-porco e mucuna-preta, respectivamente. A vegetação espontânea foi cortada no mesmo dia em que a mucuna-preta. As plantas foram cortadas rente à superfície do solo em uma área útil de $1 \mathrm{~m}^{2}$ no centro da parcela e pesadas para determinar a produtividade de massa fresca da parte aérea (em Mg ha-1). Posteriormente foram separadas amostras de $300 \mathrm{~g}$ do material coletado em cada parcela, picado em pedaços e homogeneizado, retirando-se destas uma subamostra de $100 \mathrm{~g}$, levadas à estufa de circulação forçada de ar a 65 C até atingir massa constante e pesadas para a determinação da massa seca. Com os dados da massa seca foi possível estimar a produtividade de massa seca (em $\mathrm{Mg} \mathrm{ha}^{-1}$ ).

As determinações das variáveis físicas (densidade e resistência do solo à penetração) e da umidade foram realizadas 30 dias após o corte da mucuna-preta e vegetação espontânea, tanto no primeiro como no segundo ano. Para determinação da densidade do solo $\left(\mathrm{em} \mathrm{Mg} \mathrm{m}^{-3}\right.$ ), utilizou-se o método do anel 
volumétrico. Foram coletadas amostras indeformadas nas profundidades de $0-10$ e $10-20 \mathrm{~cm}$ em todas as parcelas experimentais de acordo com a recomendação da EMBRAPA (2011).

Para avaliação da resistência do solo a penetração (em MPa), foi utilizado um penetrômetro de impacto (modelo IAA/Planalsucar-Stolf). Os ensaios de resistência foram realizados nas profundidades de 0 20 e 20-40 cm, onde também foram coletadas amostras deformadas de solo para determinação da umidade gravimétrica (em \%), de acordo com a metodologia descrita pela EMBRAPA (2011). Os dados obtidos nas amostragens em campo foram analisados no programa computacional de dados em Excel-VBA (STOLF et al., 2014), que realiza os cálculos de acordo com de Stolf (1991).

Os dados foram submetidos à análise de variância e as médias foram comparadas pelos testes de Duncan (produtividade, resistência do solo à penetração) e Tukey (umidade, densidade) ao nível de 5\% de probabilidade utilizando o software estatístico InfoStat ${ }^{\circledR} 2018$ e os gráficos plotados no SigmaPlot 14.0. Também foi realizada a análise de correlação de Pearson $(p \leq 0,05)$ entre os atributos umidade do solo e resistência à penetração, para as diferentes profundidades e para os dois anos de cultivo.

\section{RESULTADOS E DISCUSSÃO}

Neste estudo, observou-se que não houve interação entre coberturas e anos de cultivo para os parâmetros avaliados, o que implica que tais fatores atuaram de maneira independente.

Não houve diferença entre os anos de cultivo para a produtividade de massa fresca (MF) e massa seca (MS) (Tabela 3). Entre os tipos de cobertura, o feijão-de-porco e a mucuna-preta apresentaram produtividade de MF e MS iguais, porém superiores à do feijão caupi. Rodrigues et al. (2012), avaliando a matéria da parte aérea de adubos verdes, também não constataram diferenças na produtividade de MF e MS entre o feijão-de-porco e a mucuna-preta. Os menores valores de produtividade foram obtidos pelo feijão caupi, com valores de 1,55 e 0,29 $\mathrm{Mg} \mathrm{ha}^{-1}$, para a MF e MS, respectivamente. Esses resultados estão relacionados ao menor tempo de acúmulo de nutrientes, haja vista que essa leguminosa é de ciclo precoce, e seu hábito de crescimento, embora seja indeterminado, possui porte semiereto com ramos curtos.

Tabela 3: Produtividade de fitomassa fresca e seca das coberturas mucuna-preta, feijão-de-porco e feijão caupi em dois anos de cultivo em um LAd sem práticas de correção e adubação, Chapadinha, MA, Brasil

\begin{tabular}{|c|c|c|c|c|c|c|c|c|}
\hline \multirow{2}{*}{ Variável } & \multirow{2}{*}{ Cobertura } & \multicolumn{2}{|l|}{ Ano } & \multirow{2}{*}{ Média } & \multirow{2}{*}{ CV (\%) } & \multicolumn{3}{|c|}{ Probabilidade } \\
\hline & & 10 & 20 & & & Cobertura & Ano & CXA \\
\hline \multirow{4}{*}{$\begin{array}{l}\text { Massa fresca } \\
\left(\mathrm{Mg} \mathrm{ha}^{-1}\right)\end{array}$} & Mucuna-preta & 4,66 & 7,12 & $5,89 a$ & & & & \\
\hline & Feijão-de-porco & 9,44 & 9,27 & $9,36 \mathrm{a}$ & 24,26 & 0,0023 & 0,2111 & 0,0562 \\
\hline & Feijão caupí & 1,55 & 1,56 & $1,55 \mathrm{~b}$ & & & & \\
\hline & Média & $5,22 \mathrm{~A}$ & $5,98 \mathrm{~A}$ & & & & & \\
\hline \multirow{4}{*}{$\begin{array}{l}\text { Massa seca } \\
\left(\mathrm{Mg} \mathrm{ha}^{-1}\right)\end{array}$} & Mucuna-preta & 1,30 & 1,70 & $1,50 \mathrm{a}$ & & & & \\
\hline & Feijão-de-porco & 1,75 & 1,93 & $1,84 \mathrm{a}$ & 32,52 & 0,0025 & 0,2148 & 0,3577 \\
\hline & Feijão caupí & 0,33 & 0,25 & $0,29 \mathrm{~b}$ & & & & \\
\hline & Média & $1,13 \mathrm{~A}$ & $1,30 \mathrm{~A}$ & & & & & \\
\hline
\end{tabular}

*Médias seguidas de letras iguais maiúsculas na linha e minúsculas na coluna não diferem entre si pelo teste Duncan ( $p$ $<0,05)$.

No primeiro ano de cultivo as coberturas não promoveram diferenças na densidade do solo (Ds), tanto na profundidade de 0-10 cm quanto na de 10-20 cm (Tabela 4). Segundo Marchini et al. (2015) e Silva et al. (2017), a prática de adubação verde tem efeitos sobre a redução da Ds, mas esses efeitos só são 
observados de médio à longo prazo. Entretanto, comparando-se os dois anos de cultivo, verificou-se que no segundo ano houve uma redução na Ds na profundidade de 0-10 cm. Esse resultado está de acordo com os obtidos por Hossain et al. (2015), que identificaram uma redução da Ds com o cultivo de plantas de cobertura. Tal redução da Ds está associada à deposição de resíduos vegetais, uma vez que as coberturas foram manejadas e deixadas sobre o solo, além da maior quantidade de raízes presentes nessa profundidade, proporcionando uma redução da Ds na profundidade mais superficial.

Tabela 4: Densidade do solo $\left(\mathrm{Mg} \mathrm{m}^{-3}\right)$ nas profundidades de $0-10$ e 10-20 cm após 1ㅇ e 2ㅇaㅇ ano de cultivo das coberturas mucuna-preta, feijão-de-porco e feijão caupi em Chapadinha, MA, Brasil

\begin{tabular}{|c|c|c|c|c|c|c|c|c|}
\hline \multirow{2}{*}{ Variável } & \multirow{2}{*}{ Cobertura } & \multicolumn{2}{|l|}{ Ano } & \multirow{2}{*}{ Média } & \multirow{2}{*}{ CV (\%) } & \multicolumn{3}{|c|}{ Probabilidade } \\
\hline & & 10 & 20 & & & Cobertura & Ano & CxA \\
\hline \multirow{5}{*}{$\begin{array}{l}\text { Densidade } \\
(0-10 \mathrm{~cm})\end{array}$} & Mucuna-preta & 1,51 & 1,45 & $1,48 \mathrm{a}$ & \multirow{4}{*}{4,11} & \multirow{4}{*}{0,4298} & \multirow{4}{*}{0,0025} & \multirow{4}{*}{0,366} \\
\hline & Feijão-de-porco & 1,54 & 1,51 & $1,52 \mathrm{a}$ & & & & \\
\hline & Feijão caupi & 1,58 & 1,46 & $1,52 \mathrm{a}$ & & & & \\
\hline & Veg. espontânea & 1,52 & 1,48 & $1,50 \mathrm{a}$ & & & & \\
\hline & Média & $1,54 \mathrm{~A}$ & $1,47 \mathrm{~B}$ & & & & & \\
\hline \multirow{5}{*}{$\begin{array}{l}\text { Densidade } \\
(10-20 \mathrm{~cm})\end{array}$} & Mucuna-preta & 1,58 & 1,59 & $1,59 a$ & \multirow{4}{*}{4,34} & \multirow{4}{*}{0,3144} & \multirow{4}{*}{0,2851} & \multirow{4}{*}{0,7704} \\
\hline & Feijão-de-porco & 1,60 & 1,59 & $1,60 \mathrm{a}$ & & & & \\
\hline & Feijão caupi & 1,67 & 1,62 & $1,64 \mathrm{a}$ & & & & \\
\hline & Veg. espontânea & 1,61 & 1,57 & $1,59 a$ & & & & \\
\hline & Média & $1,62 \mathrm{~A}$ & $1,59 \mathrm{~A}$ & & & & & \\
\hline
\end{tabular}

*Médias seguidas de letras iguais maiúsculas na linha e minúsculas na coluna não diferem entre si pelo teste Tukey ( $p$ $<0,05)$.

Houve aumento da Ds no primeiro ano de cultivo em relação à análise inicial (Tabela 2). As Ds médias para a maioria das coberturas foram superiores a $1,5 \mathrm{Mg} \mathrm{m}^{-3}$, valores considerados altos para solos arenosos (RAIJ, 2011), indicando que o solo está compactado, sobretudo na profundidade de $10-20 \mathrm{~cm}$ onde são observados os maiores valores.

Os teores de umidade do solo nas profundidades de 0-20 e 20-40 cm foram diferentes entre os anos de cultivo (Figura 2A), com o segundo ano apresentando os maiores valores (8,13 e 9,86\%, respectivamente). Na profundidade de $0-20 \mathrm{~cm}$, a área sob o cultivo da vegetação espontânea apresentou maior teor de umidade $(8,71 \%)$ em relação ao do feijão caupi $(6,95 \%)$, não diferindo das demais áreas (Figura 2B). No entanto para a profundidade de $20-40 \mathrm{~cm}$ os teores de umidade foram iguais entre os tipos de cobertura.

A maior umidade gravimétrica do solo para o segundo ano pode ser atribuída à precipitação pluviométrica nos dias antecedentes às amostragens em campo para a determinação dessa variável. Já em relação à variação das médias de umidade na profundidade superficial do solo $(0-20 \mathrm{~cm})$, deve-se a maior quantidade de areia grossa e fina nessa profundidade (Tabela 1), que proporciona uma menor retenção da água do solo, sendo determinante a presença dos resíduos vegetais como cobertura, tornando-se uma barreira impeditiva para perda de água por evaporação.

Para a resistência a penetração $(R)$ na profundidade de 0-20 cm, não houve diferença entre os anos de cultivo, com média de 2,38 e 2,10 MPa, para o primeiro e segundo ano, respectivamente (Figura 2C). Para essa variável as menores médias foram da vegetação espontânea (2,05 MPa) e mucuna-preta (2,13 $\mathrm{MPa})$, contudo essas coberturas diferiram apenas do feijão caupi (2,47 MPa) (Figura 2D). Esse maior valor de $R$ apresentado pelo feijão caupi pode estar relacionado à sua baixa produtividade de biomassa, atrelado a uma 
menor umidade do solo no momento dos ensaios de R. Houve uma pequena redução da $\mathrm{R}$ em relação à análise inicial (Tabela 2), que de acordo com Passos et al. (2017), tais resultados devem-se a curta duração dos ciclos de cultivo em campo, e que os efeitos sobre essa variável possivelmente seriam significativos a longo prazo.

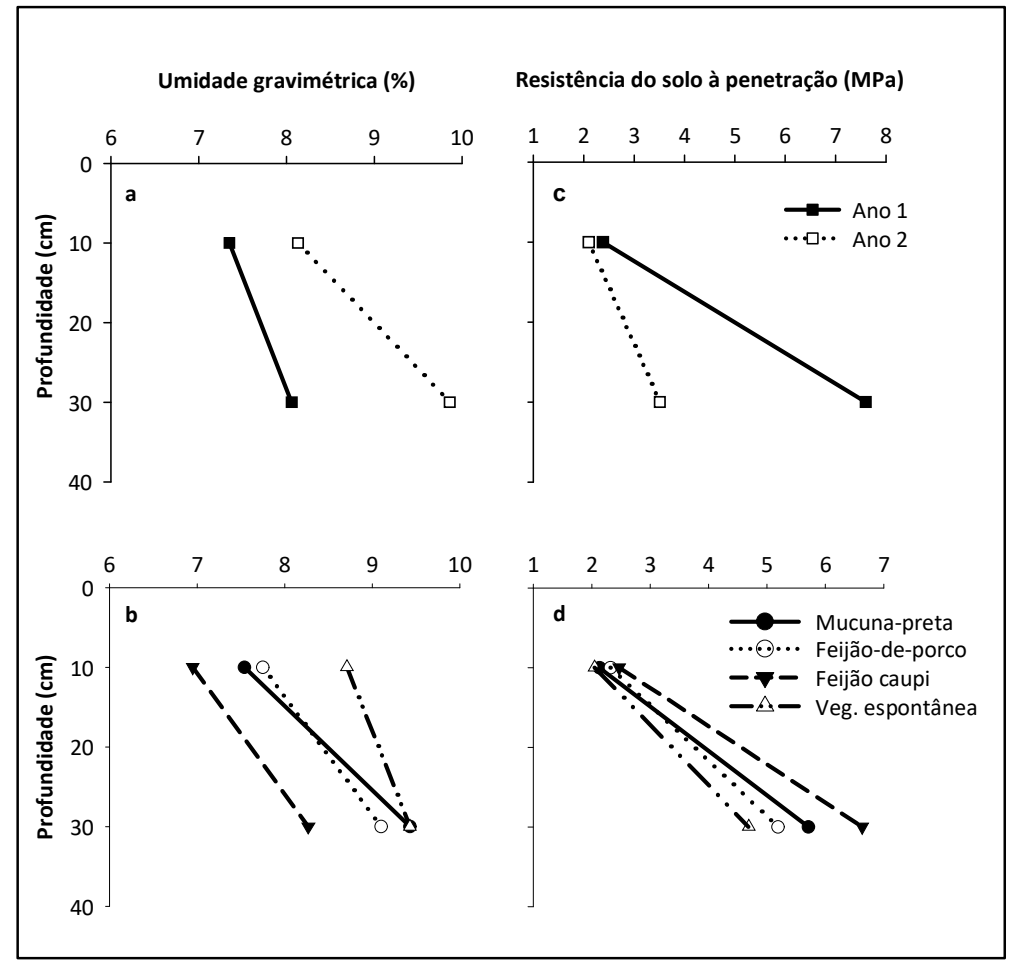

Figura 2: Umidade do solo ( $A$ e $B$ ) e resistência à penetração ( $C$ e D) nas profundidades de 0-20 e 20-40 cm após 10 e 20 ano de cultivo das coberturas mucuna-preta, feijão-de-porco e feijão caupi em Chapadinha, MA, Brasil.

Na profundidade de $20-40 \mathrm{~cm}$ a $R$ foi significativamente mais elevada no primeiro ano (7,60 MPa) do que segundo ano (3,51 MPa), sendo que a cobertura que apresentou a maior média de $R$ foi o feijão caupi (6,63 MPa) e a menor foi a vegetação espontânea (4,69 MPa), havendo diferença apenas entre essas duas coberturas, o que pode ser atribuído a baixa produtividade de fitomassa do feijão caupi, além de um menor volume de raízes nessa profundidade, já que essa cultivar não possui um sistema radicular vigoroso.

Os valores da R da profundidade de $20-40 \mathrm{~cm}$ de acordo com Moraes et al. (2014) são considerados críticos ao desenvolvimento radicular das culturas independente do sistema de cultivo utilizado. Tais diferenças nos resultados dos dois anos de cultivo, podem estar relacionadas à maior umidade no momento da amostragem, que refletiu diretamente nos valores de R, que de acordo com Silveira et al. (2010), pequenos aumentos nos valores de umidade proporcionam grandes reduções da resistência à penetração.

De acordo com a correlação de Pearson, a R apresentou correlação negativa com a umidade do solo, independente do ano de cultivo e da profundidade avaliada (Tabela 5). As menores correlações foram observadas para a profundidade de $0-20 \mathrm{~cm}$ tanto no primeiro como no segundo ano de cultivo, indicando que a $\mathrm{R}$ dessa profundidade foi pouco influenciada pela umidade do solo. Por outro lado, na camada de 20$40 \mathrm{~cm}$ a $\mathrm{R}$ e fortemente afetada pela umidade do solo no momento das amostragens.

Com a análise comparativa entre os dois anos de cultivo, foi possível observar diferenças apenas para a Ds na profundidade de 0-10 cm e para a R na profundidade de $20-40 \mathrm{~cm}$. Contudo, ao analisar os valores 
de Ds e R da análise prévia (Tabela 2), podemos observar valores próximos ao do 2ํano para essas variáveis. Além disso, com a retirada da vegetação nativa para inserção de plantas de cobertura cultivadas, ocorreu aumentos da Ds nas camadas de 0-10 e 10-20 cm, e na R nas camadas de 20-40 cm devido a perturbação do solo pela ação atrópica na área de cultivo, como evidenciado no 10 ano de cultivo. Por outro lado, observase reduções da $\mathrm{R}$ na camada de 0-20 cm mesmo sob umidade do solo mais baixa, indicando uma diminuição na $\mathrm{R}$ com os anos de cultivo.

Tabela 5: Correlação de Pearson entre os atributos umidade e resistência do solo à penetração nas profundidades 0-20 e $20-40 \mathrm{~cm}$, em dois anos de cultivo.

\begin{tabular}{lll}
\hline \multirow{2}{*}{ Umidade } & \multicolumn{2}{l}{ Resistência à penetração } \\
\cline { 2 - 3 } & $0-20 \mathrm{~cm}$ & $20-40 \mathrm{~cm}$ \\
\hline Ano 1 & $-0,24^{\mathrm{ns}}$ & $-0,63^{* *}$ \\
Ano 2 & $-0,28^{\text {ns }}$ & $-0,81^{* * *}$ \\
\hline ns; ${ }^{* *} ; * * *$ & não significativo a $5 \%$, significativo a $1 \%$ e a $0,1 \%$, respectivamente.
\end{tabular}

Embora não tenha sido observada diferenças entre as coberturas vegetação espontânea, mucunapreta e feijão-de-porco quanto à densidade do solo e resistência à penetração nas duas profundidades estudadas, vale ressaltar que, o solo manejado com leguminosas possui maior valorização em comparação àqueles mantido com plantas espontâneas, pois contribuem para redução do banco de sementes do solo, diminuindo a infestação de plantas espontâneas durante o cultivo de plantas de interesse econômico, especialmente em sistemas de cultivo onde não é feito o uso de herbicidas para o seu controle.

\section{CONCLUSÕES}

Portanto, dentre as leguminosas avaliadas, a mucuna-preta e o feijão-de-porco possuem melhores potenciais produtivo de fitomassa. Nas condições edafoclimáticas do estudo, as coberturas não proporcionam alterações nos atributos físicos do solo, com exceção do feijão caupi que apresentou efeitos negativos, não sendo recomendado como cobertura, quando se objetiva a melhoria das propriedades físicas do solo. Os anos de cultivo contribuíram para uma melhora nos atributos físicos do solo, reduzindo a densidade e a resistência à penetração.

\section{REFERÊNCIAS}

CARDOSO, R. A.; BENTO, A. S.; MORESKI, H. M.; GASPAROTTO, F.. Influência da adubação verde nas propriedades físicas e biológicas do solo e na produtividade da cultura de soja. Semina: Ciências Biológicas e da Saúde, v.35, n.2, p.51-60, 2014. DOI:

http://dx.doi.org/10.5433/1679-0367.2014v35n2p51

CASTRO, C. N.. A agricultura no nordeste brasileiro: oportunidades e limitações ao desenvolvimento. Rio de Janeiro: Ipea, 2012.

CHERUBIN, M. R.; EITELWEIN, M. T.; FABBRIS, C.; WEIRICH, S. W.; SILVA, R. F.; SILVA, V. R.; BASSO, C. J.. Qualidade física, química e biológica de um Latossolo com diferentes manejos e fertilizantes. Revista Brasileira de Ciência do Solo, v.39, p.615-625, 2015.
COSTA, Y. T.; RODRIGUES, S. C.. Efeito do fogo sobre vegetação e solo a partir de estudo experimental em ambiente de Cerrado. Revista do Departamento de Geografia, v.30, p.149-165, 2015.

DANTAS, J. S; MARQUES JÚNIOR, J.; MARTINS FILHO, M. V.; RESENDE, J. M. A.; CAMARGO, L. A.; BARBOSA, R. S.. Gênese de solos coesos do leste maranhense: relação solopaisagem. Revista Brasileira de Ciência do Solo, v.38, n.4, p.1039-1050, 2014. DOI: http://dx.doi.org/10.1590/S0100$\underline{06832014000400001}$

EMBRAPA, Empresa Brasileira de Pesquisa Agropecuária. Manual de métodos de análise de solos. Rio de Janeiro: Embrapa Solos, 2011. 
FARIAS, M. F.; FEITOSA, C. E. L.; RODRIGUES, K. M.; TEIXEIRA, L. C.; FURTADO, M. B.; PARRA-SERRANO, L. J.. Impact of management on the physical attributes of a dystrophic Yellow Latosol. Journal of Agricultural Science, v.9, n.5, p.217-225, 2017. DOI: http://doi.org/10.5539/jas.v9n5p217

HOSSAIN, M D. A.; AKAMINE, H.; TAMAKI, M.. Green manure plants influence growth, yield and curcumin content of turmeric (Curcuma longa L.) in Dark-red Soil in Okinawa, Japan. Tropical Agriculture and Development, v.59, n.2, p.63-75, 2015. DOI: https://doi.org/10.11248/jsta.59.63

INMET. Instituto Nacional de Meteorologia. Boletins agroclimatológicos. INMET, 2018.

JESUS, M.; HENRIQUES, P. D; LARANJEIRA, P.; NARCISO, V.; CARVALHO, M. L. S.. A agricultura itinerante no distrito de Bobonaro em Timor-leste no período pós-independência. Revista em Agronegócio e meio Ambiente, v.8, n.1, p.193215, 2015.

MARCHINI, D. C.; LING, T. C.; ALVES, M. C.; CRESTANA, S.; SOUTO FILHO, S. N.; ARRUDA, O. G.. Matéria orgânica, infiltração e imagens tomográficas de Latossolo em recuperação sob diferentes tipos de manejo. Revista Brasileira de Engenharia Agrícola e Ambiental, v.19, n.6, p.574-580, 2015.

MELO, V. F.; SILVA, D. T.; EVALD, A.; ROCHA, P. R. R.. Qualidade química e biológica do solo em diferentes sistemas de uso em ambiente de savana. Revista Agro@mbiente, v.11, n.2, p.101-110, 2017.

MORAES, M. T.; DEBIASI, H.; CARLESSO, R.; FRANCHINI, J. C.; SILVA, V. R.. Critical limits of soil penetration resistance in a Rhodic Eutrudox. Revista Brasileira de Ciência do Solo, v.38, p.288-298, 2014.

MOURA, E. G.; GEHRING, C.; BRAUN, H.; FERRAZ JUNIOR, A. S. L.; REIS, F. O.; AGUIAR, A. C. F.. Improving farming practices for sustainable soil use in the humid tropics and rainforest ecosystem health. Sustainability, v.841, n.8, p.121, 2016. DOI: https://doi.org/10.3390/su8090841

MOURA-SILVA, A. G.; AGUIAR, A. C. F.; MOURA, E. G.; JORGE, $\mathrm{N}$.. Influence of soil cover and $\mathrm{N}$ and $\mathrm{K}$ fertilization on the quality of biofortified QPM in the humid tropics. Journal of the Science of Food and Agriculture, v.96, n.11, p.38073812, 2016. DOI: http://doi.org/10.1002/isfa.7574

OLIVEIRA, D. M. S.; LIMA, R. P.; VERBURG, E. E. J.. Qualidade física do solo sob diferentes sistemas de manejo e aplicação de dejeto líquido suíno. Revista Brasileira de Engenharia Agrícola e Ambiental, v.19, n.3, p.280-285, 2015.

PASSOS, A. M. A.; AKER, A. M.; COSTA, R. S. C.; SANTOS, F. C.; LEITE, V. P. D.; MARCOLAN, A. L.. Effect of cover crops on physico-chemical attributes of soil in a short-term experiment in the southwestern Amazon region.African Journal of Agricultural Research. v.12, n.47, p.3339-3347, 2017.

PEREIRA, A. P.; SCHOFFEL, A.; KOEFENDER, J.; CAMERA, J. N.; GOLLE, D. P.; HORN, R. C.. Ciclagem de nutrientes por plantas de cobertura de verão. Revista de Ciências Agrárias, v.40, n.4, p.799-807, 2017.

RAIJ, B. V.. Solos. In: RAIJ, B. V.. Fertilidade do solo e manejo de nutrientes. Piracicaba: International Plant Nutrition Institute, 2011. p.9-38.

RODRIGUES, G. B.; SÁ, M. E.; VALÉRIO FILHO, W. V.; BUZETTI, S.; BERTOLIN, D. C.; PINA, T. P.. Matéria e nutrientes da parte aérea de adubos verdes em cultivos exclusivo e consorciado. Revista Ceres, v.59, n.3, p.380-385, 2012.

SANTOS, H. G.; JACOMINE, P. K. T.; ANJOS, L. H. C.; OLIVEIRA, V. A.; LUMBRERAS, J. F.; COELHO, M. R.; ALMEIDA, J. A.; CUNHA, T. J. F.; OLIVEIRA, J. B.. Sistema Brasileiro de Classificação de Solos. 3 ed. Brasília: Embrapa, 2013.

SILVA, M. P.; ARF, O.; SÁ, M. E.; ABRANTES, F. L.; BERTI, C. L. F.; SOUZA, L. C. D.. Plantas de cobertura e qualidade química e física de Latossolo Vermelho distrófico sob plantio direto. Revista Brasileira de Ciências Agrárias (Agraria), v.12, n.1, p.60-67, 2017. DOI: http://doi.org/10.5039/agraria.v12i1a5424

SILVEIRA, D. C.; MELO FILHO, J. F.; SACRAMENTO, J. A. A. S.; SILVEIRA, E. C. P.. Relação umidade versus resistência à penetração para um Argissolo Amarelo distorções no recôncavo da Bahia. Revista Brasileira de Ciência do Solo, v.34, n.3, p.659-667, 2010. DOI: http://dx.doi.org/10.1590/S0100-06832010000300007

SOUZA, L. S.; BORGES, A. L.; SOUZA, L. D.. Influência da Adubação verde em aspectos físicos, químicos e biológicos do solo. In: TOFANELLI, M. B. D.; SILVA, T. O.. Manejo ecológico e conservação dos solos e da água no Estado de Sergipe. São Cristóvão: UFS, 2011. p.115-142.

STOLF, R.; MURAKAMI, J. H.; BRUGNARO, C.; SILVA, L. G.; SILVA, L. C. F.; MARGARIDO, L. A. C.. Penetrômetro de Impacto Stolf - programa de manipulação de dados em Excel-VBA. Revista Brasileira de Ciência do solo, v.30, n.3, p.774-782, 2014. DOI: http://dx.doi.org/10.1590/S0100$\underline{06832014000300009}$

STOLF, R.. Teoria e teste experimental de fórmulas de transformação dos dados de penetrômetro de impacto em resistência do solo. Revista Brasileira de Ciência do Solo, v.15, n.2, p.229-235, 1991.

A CBPC - Companhia Brasileira de Produção Científica (CNPJ: 11.221.422/0001-03) detém os direitos materiais desta publicação. Os direitos referem-se à publicação do trabalho em qualquer parte do mundo, incluindo os direitos às renovações, expansões e disseminações da contribuição, bem como outros direitos subsidiários. Todos os trabalhos publicados eletronicamente poderão posteriormente ser publicados em coletâneas impressas sob coordenação da Sustenere Publishing, da Companhia Brasileira de Produção Científica e seus parceiros autorizados. Os (as) autores (as) preservam os direitos autorais, mas não têm permissão para a publicação da contribuição em outro meio, impresso ou digital, em português ou em tradução. 